\title{
Endoscopic Diagnosis of Gastric MALT Lymphoma
}

\author{
Kouichi Nonaka*, Ken Ohata, Nobuyuki Matsuhashi \\ Department of Gastroenterology, NTT Medical Center, Tokyo, Japan \\ Email: nonaka513@gmail.com
}

Received 10 March 2014; revised 5 April 2014; accepted 12 April 2014

Copyright (C) 2014 by authors and Scientific Research Publishing Inc.

This work is licensed under the Creative Commons Attribution International License (CC BY). http://creativecommons.org/licenses/by/4.0/

c) (i) Open Access

\begin{abstract}
The endoscopic findings of gastric MALT lymphoma are variable, making its diagnosis very difficult. Although there are many reports on the endoscopic findings of gastric cancer, there are few on those of gastric MALT lymphoma. Herein, we summarize the reports on the endoscopic findings of gastric MALT lymphoma, and report its endoscopic diagnosis.
\end{abstract}

\section{Keywords}

\section{MALT, Endoscopy}

\section{Introduction}

Gastric lymphoma arising from mucosa-associated lymphoid tissue (MALT) was first reported as a low-grade gastric lymphoma in 1983 by Isaacso [1]. MALT lymphoma has distinct histological and clinical characteristics compared with nodal B-cell lymphoma [1]-[3]. MALT lymphoma arising in the stomach grossly presents as a flat, superficial, or even invasive lesion with erosions and ulcerations, and develops from chronic active gastritis. Gastric MALT lymphoma is often misdiagnosed endoscopically as a gastric ulcer, gastritis, or gastric cancer, and it is necessary to establish the diagnosis of gastric MALT lymphoma from these diseases. It is important to initially suspect gastric MALT lymphoma because of the various macroscopic patterns, even when multiple biopsies cannot yield a definitive diagnosis of MALT lymphoma.

It was reported that $10 \%-20 \%$ of cases on initial endoscopy and $50 \%-70 \%$ of cases on biopsies were diagnosed as MALT lymphoma [4]. One of the reasons for misdiagnosis might be the low incidence of stomach MALT lymphoma, that is, $2 \%-8 \%$, within gastric malignant disease [5].

There are few organized reports on the endoscopic findings of gastric MALT lymphoma [6]-[8], with only a few case reports published on its diverse endoscopic findings [9]-[11]. Recent studies have reported the useful-

"Corresponding author. 
ness of NBI magnifying endoscopy in diagnosing gastric MALT lymphoma [12]-[15]. In addition, the usefulness of endoscopic ultrasound findings as a predictor of the therapeutic efficacy of $H$. pylori eradication has been reported [16] [17]. In this review, we summarize these reports, and report the endoscopic diagnosis of gastric MALT lymphoma.

\section{Conventional Endoscopy}

The conventional endoscopic findings of gastric MALT lymphoma vary widely, ranging from ulcerative or gastritis-like lesions to those resembling depressed early gastric cancer, or elevated lesions (Figure 1). In some cases, more than one gross pathologic type of gastric MALT lymphoma coexists in the same stomach. There are also case reports of patients presenting with multiple lymphomatous polyposis (MLP), which is often observed in mantle cell lymphoma [9] [11]. Zullo et al. [6] classified gastric MALT lymphoma into ulcerative, exophytic, hypertrophic, mixed, petechial hemorrhage, and normal/hyperemic types. In Japan, gastric MALT lymphoma has been classified into early-stage gastric carcinoma-like, gastritis-like, and submucosal tumor-like patterns [14] [18]; into superficial (including superficial ulcer, erosion, gastritis, discolored area, early cancer-like, and cobblestone types), mass, and mixed types [15]; and into superficial and SMT-like types [19].

However, it is not easy to classify the wide variety of endoscopic findings by type.

The common conventional endoscopic findings of $\mathrm{H}$. pylori eradication-resistant gastric MALT lymphioma were elevated submucosal lesions [20]. If the remission of gastric MALT lymphoma is achieved after H. pylori eradication or irradiation, endoscopy reveals a scar (Figure 2).

\section{Narrow Band Imaging}

Narrow band imaging (NBI) is a new image enhancement system employing optic digital methods to enhance images of blood vessels on mucosal surfaces, allowing the improved visualization of mucosal surface structures. Studies have progressed over the last several years, and the clinical usefulness has been demonstrated [21] [23].

In 2009, we reported a case of gastric mucosa-associated lymphoid tissue (MALT) lymphoma presenting with unique vascular features [12]. In the report, we defined the tree-like appearance (TLA) on the images of abnormal blood vessels which resembled branches from the trunk of a tree in the shiny mucosa, in which the glandular structure was lost (Figure 3). Norimura et al. also reported similar findings in 2012 [24].

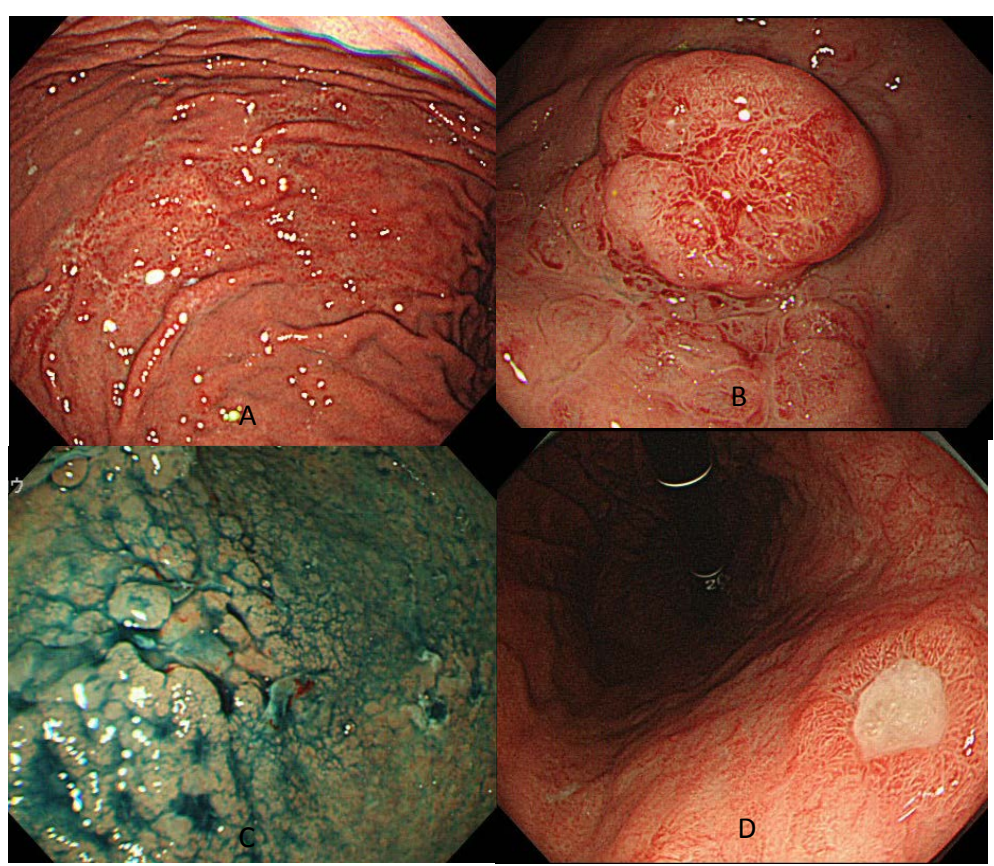

Figure 1. Various endoscopic findings of gastric MALT lymphoma. (A) Gastritis-like pattern; (B) SMT-like pattern; (C) Early gastric cancer-like pattern; (D) Ulcer-like pattern. 


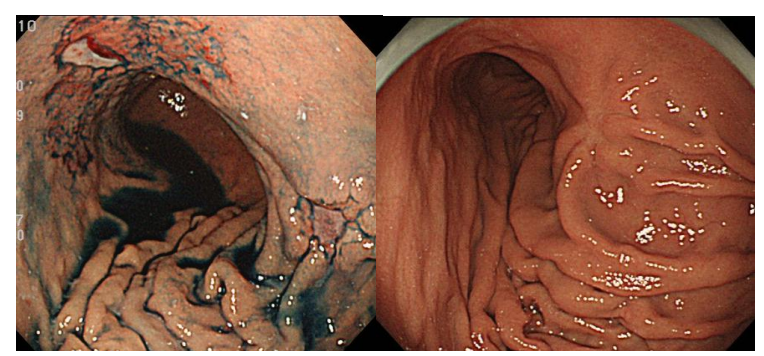

Figure 2. Changes in findings of MALT lymphoma on conventional endoscopy after successful eradication therapy. Scars with fold convergence were formed after successful eradication therapy.

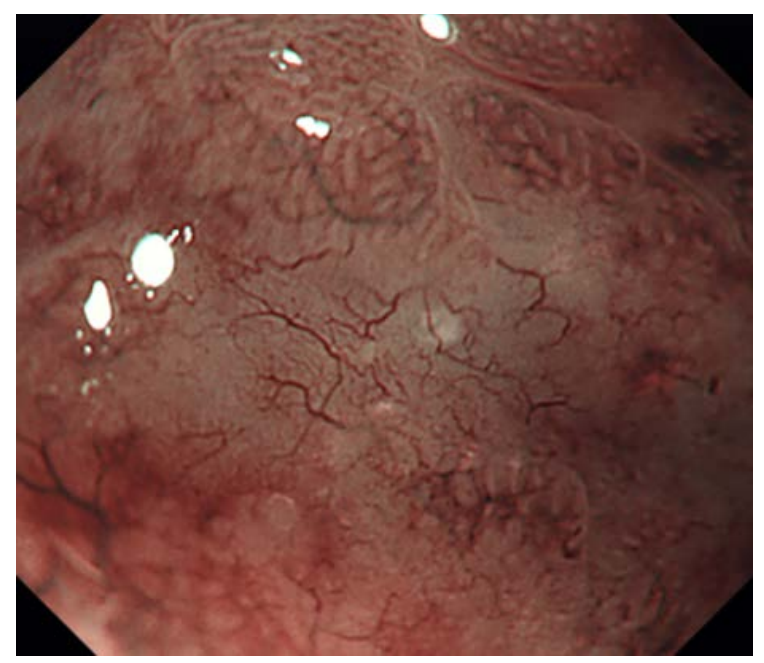

Figure 3. We defined the tree-like appearance (TLA) on the images of abnormal blood vessels which resembled branches from the trunk of a tree in the shiny mucosa, in which the glandular structure was lost.

TLA observed in gastric MALT lymphoma is useful for differentiation from undifferentiated-type early gastric cancer and gastritis, which is difficult by conventional observation 21.

Therefore, we have clearly shown that target biopsies from a suspected MALT lymphoma based on ME with NBI are useful in the histological diagnosis of gastric MALT lymphoma 13.

As experience with patient treatment increased, we found that gastric MALT lymphoma without TLA existed, with the result that TLA was observed in 75\% of gastric MALT lymphomas 14 . In that study, $H$. pylori eradication therapy was performed in 12 patients showing TLA to examine the relationship between changes in NBI findings and the efficacy of $H$. pylori eradication.

TLA disappeared in all 8 patients in whom no residual MALT lymphoma was observed on biopsy after therapy, whereas TLA remained in all 4 patients in whom residual MALT lymphoma was noted on biopsy ( $\mathrm{p}=$ 0.002 ), showing that the sensitivity and specificity were $100 \%$.

NBI magnifying endoscopy is an essential means of diagnosing gastric MALT lymphoma.

\section{Endoscopic Ultrasonography}

Nakamura et al. [16] considered that evaluation of the depth of SM invasion by endoscopic ultrasonography (EUS) was useful for the prediction of the efficacy of $H$. pylori eradication therapy: the remission rate was 93\% in patients diagnosed with mucosal (M) lesions by EUS, whereas it was only $23 \%$ in those with submucosal (SM) or deeper lesions (Figure 4). EUS was also reported to be useful for determining the healing of gastric MALT lymphoma [25]. 


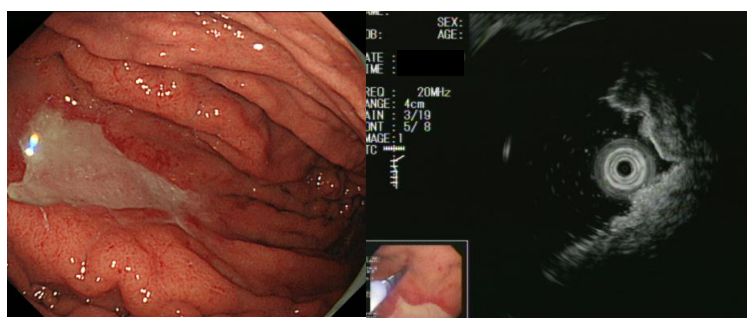

Figure 4. Endoscopic ultrasonography findings of gastric MALT lymphoma. A) Conventional endoscopy revealed an ulcerative lesion with fur in the greater curvature of the upper gastric corpus; B) EUS showed that the fourth layer was obscured, suggesting that MALT lymphoma had invaded the muscular and deeper layers.

\section{Conclusion}

Although further studies involving more patients are needed, the use of NBI, which has been reported to be useful in the endoscopic diagnosis of gastrointestinal tumors over the last several years, has enabled the diagnosis of gastric MALT lymphoma with a high degree of accuracy. The endoscopic appearances of gastric MALT lymphoma are so varied that it is undoubtedly difficult to establish a diagnosis by conventional endoscopy alone. To make a definitive diagnosis of gastric MALT lymphoma, it is essential to include gastric MALT lymphoma first in the differential diagnoses of lesions identified by conventional endoscopy, particularly when multiple and variable gastric lesions are observed. It is recommended that NBI magnifying endoscopy be performed at the time of suspicion of gastric MALT lymphoma to select an appropriate biopsy site. At present, EUS findings alone can be used to predict the therapeutic efficacy of $\mathrm{H}$. pylori eradication; therefore, it is recommended that EUS be performed, whenever possible, for the pretreatment evaluation of gastric MALT lymphoma. Needless to say, it is necessary for gastric MALT lymphoma to be comprehensively diagnosed by a combination of conventional endoscopy and diagnostic aids, such as NBI and EUS, and treated.

\section{References}

[1] Isaacson, P., Wright, D.H. and Jones, D.B. (1983) Malignant Lymphoma of True Histiocytic (Monocyte/Macrophage) Origin. Cancer, 51, 80-91. http://dx.doi.org/10.1002/1097-0142(19830101)51:1<80::AID-CNCR2820510118>3.0.CO;2-0

[2] Wotherspoon, A.C., Doglioni, C. and Isaacson, P.G. (1992) Low-Grade Gastric B-Cell Lymphoma of Mucosa-Associated Lymphoid Tissue (MALT): A Multifocal Disease. Histopathology, 20, 29-34. http://dx.doi.org/10.1111/j.1365-2559.1992.tb00912.x

[3] Wotherspoon, A.C., Finn, T.M. and Isaacson, P.G. (1995) Trisomy 3 in Low-Grade B-Cell Lymphomas of MucosaAssociated Lymphoid Tissue. Blood, 85, 2000-2004.

[4] Taal, B.G., Boot, H., van Heerde, P., de Jong, D., Hart, A.A. and Burgers, J.M. (1996) Primary Non-Hodgkin Lymphoma of the Stomach: Endoscopic Pattern and Prognosis in Low Versus High Grade Malignancy in Relation to the MALT Concept. Gut, 39, 556-561. http://dx.doi.org/10.1136/gut.39.4.556

[5] Zucca, E. and Cavalli, F. (2000) Extranodal Lymphomas. Annals of Oncology: Official Journal of the European Society for Medical Oncology/ESMO, 11, 219-222.

[6] Zullo, A., Hassan, C., Andriani, A., et al. (2010) Primary Low-Grade and High-Grade Gastric MALT-Lymphoma Presentation. Journal of Clinical Gastroenterology, 44, 340-344.

[7] Ahmad, A., Govil, Y. and Frank, B.B. (2003) Gastric Mucosa-Associated Lymphoid Tissue Lymphoma. The American Journal of Gastroenterology, 98, 975-986. http://dx.doi.org/10.1111/j.1572-0241.2003.07424.X

[8] Kolve, M., Fischbach, W., Greiner, A. and Wilms, K. (1999) Differences in Endoscopic and Clinicopathological Features of Primary and Secondary Gastric Non-Hodgkin's Lymphoma. German Gastrointestinal Lymphoma Study Group. Gastrointestinal Endoscopy, 49, 307-315. http://dx.doi.org/10.1016/S0016-5107(99)70006-4

[9] Chim, C.S., Shek, T.W., Chung, L.P. and Liang, R. (2003) Unusual Abdominal Tumors: Case 3. Multiple Lymphomatous Polyposis in Lymphoma of Colon. Journal of Clinical Oncology: Official Journal of the American Society of Clinical Oncology, 21, 953-955. http://dx.doi.org/10.1200/JCO.2003.02.032

[10] Tomizawa, Y., Seki, M. and Mori, M. (2012) Unusual Presentation of Localized Gastric Mucosa-Associated Lymphoid 
Tissue Lymphoma Mimicking Poorly Differentiated Gastric Adenocarcinoma. Case Reports in Gastroenterology, 6, 47-51. http://dx.doi.org/10.1159/000336322

[11] Chen, C.H. and Pai, R. (2012) Unusual Presentation of MALT Lymphoma as Diffuse Gastric Erythema. Gastrointestinal Endoscopy, 75, 422-423. http://dx.doi.org/10.1016/j.gie.2011.10.011

[12] Nonaka, K., Ishikawa, K., Shimizu, M., et al. (2009) Education and Imaging. Gastrointestinal: Gastric Mucosa-Associated Lymphoma Presented with Unique Vascular Features on Magnified Endoscopy Combined with Narrow-Band Imaging. Journal of Gastroenterology and Hepatology, 24, 1697. http://dx.doi.org/10.1111/j.1440-1746.2009.06030.x

[13] Nonaka, K., Ishikawa, K., Arai, S., et al. (2012) A Case of Gastric Mucosa-Associated Lymphoid Tissue Lymphoma in Which Magnified Endoscopy with Narrow Band Imaging Was Useful in the Diagnosis. World Journal of Gastrointestinal Endoscopy, 4, 151-156. http://dx.doi.org/10.4253/wjge.v4.i4.151

[14] Nonaka, K., Ohata, K., Matsuhashi, N., et al. (2013) Is Narrow-Band Imaging Useful for Histological Evaluation of Gastric Mucosa-Associated Lymphoid Tissue Lymphoma after Treatment? Digestive Endoscopy: Official Journal of the Japan Gastroenterological Endoscopy Society.

[15] Ono, S., Kato, M., Ono, Y., et al. (2011) Target Biopsy Using Magnifying Endoscopy in Clinical Management of Gastric Mucosa-Associated Lymphoid Tissue Lymphoma. Journal of Gastroenterology and Hepatology, 26, 1133-1138. http://dx.doi.org/10.1111/j.1440-1746.2011.06729.x

[16] Nakamura, S., Matsumoto, T., Suekane, H., et al. (2001) Predictive Value of Endoscopic Ultrasonography for Regression of Gastric Low Grade and High Grade MALT Lymphomas after Eradication of Helicobacter Pylori. Gut, 48, 454460. http://dx.doi.org/10.1136/gut.48.4.454

[17] Sackmann, M., Morgner, A., Rudolph, B., et al. (1997) Regression of Gastric MALT Lymphoma after Eradication of Helicobacter Pylori Is Predicted by Endosonographic Staging. MALT Lymphoma Study Group. Gastroenterology, 113, 1087-1090. http://dx.doi.org/10.1053/gast.1997.v113.pm9322502

[18] Akamatsu, T., Mochizuki, T., Okiyama, Y., Matsumoto, A., Miyabayashi, H. and Ota, H. (2006) Comparison of Localized Gastric Mucosa-Associated Lymphoid Tissue (MALT) Lymphoma with and without Helicobacter Pylori Infection. Helicobacter, 11, 86-95. http://dx.doi.org/10.1111/j.1523-5378.2006.00382.x

[19] Asano, N., Iijima, K., Terai, S., et al. (2012) Eradication Therapy Is Effective for Helicobacter Pylori-Negative Gastric Mucosa-Associated Lymphoid Tissue Lymphoma. The Tohoku Journal of Experimental Medicine, 228, $223-227$. http://dx.doi.org/10.1620/tjem.228.223

[20] Yokoi, T., Nakamura, T., Kasugai, K., et al. (1999) Primary Low-Grade Gastric Mucosa-Associated Lymphoid Tissue (MALT) Lymphoma with Polypoid Appearance. Polypoid Gastric MALT Lymphoma: A Clinicopathologic Study of Eight Cases. Pathology International, 49, 702-709. http://dx.doi.org/10.1046/j.1440-1827.1999.00935.x

[21] Nonaka, K., Nishimura, M. and Kita, H. (2012) Role of Narrow Band Imaging in Endoscopic Submucosal Dissection. World Journal of Gastrointestinal Endoscopy, 4, 387-397. http://dx.doi.org/10.4253/wjge.v4.i9.387

[22] Ezoe, Y., Muto, M., Uedo, N., et al. (2011) Magnifying Narrowband Imaging Is More Accurate than Conventional White-Light Imaging in Diagnosis of Gastric Mucosal Cancer. Gastroenterology, 141, 2017-2025.

[23] Yao, K., Doyama, H., Gotoda, T., et al. (2014) Diagnostic Performance and Limitations of Magnifying Narrow-Band Imaging in Screening Endoscopy of Early Gastric Cancer: A Prospective Multicenter Feasibility Study. Gastric Cancer: Official Journal of the International Gastric Cancer Association and the Japanese Gastric Cancer Association.

[24] Norimura, D., Fukuda, E., Yamao, T., et al. (2012) Education and Imaging. Gastrointestinal: Gastric Mucosa-Associated Lymphoid Tissue (MALT) Lymphoma Observed by Magnifying Endoscopy with Narrow Band Imaging. Journal of Gastroenterology and Hepatology, 27, 987. http://dx.doi.org/10.1111/j.1440-1746.2012.07105.x

[25] Kita, H. (2007) EUS to Predict Cure of Gastric Mucosa-Associated Lymphoma after Helicobacter Pylori Eradication. Gastrointestinal Endoscopy, 65, 97-98. http://dx.doi.org/10.1016/j.gie.2006.07.024 